\title{
Koselleck, la memoria y la historia. Sobre la dificultad de entender el tiempo presente
}

\author{
Antonio Gómez Ramos
}

\section{Universidad Carlos III de Madrid}

agramos@hum.uc3m.es - https://orcid.org/0000-0003-3382-6725

Fecha recepción: 29.05.2020 / Fecha aceptación: 29.09.2020

\section{Resumen}

El ensayo analiza la relación de Koselleck con las categorías sociopolíticas ligadas a la nueva temporalidad de los últimos decenios, particularmente la memoria negativa. Koselleck fue un teórico reconocido de la modernidad y es una referencia para muchos intérpretes y críticos de nuevo cronotopo que sigue a la crisis de la modernidad. Sin embargo, él mismo se encuentra incómodo en el nuevo cronotopo. Confrontando a Koselleck con algunos de esos intérpretes -el presentismo de Hartog, la teoría de la compensación, el lento presente de Gumbrecht y política de la memoria de Assmann-, el ensayo repasa sus trabajos finales sobre la memoria y se pone de manifiesto cómo la oposición que mantuvo entre memoria e historia le colocaba en una actitud crítica respecto al presente. Irónicamente, su valentía al enfrentarse al pasado alemán

\section{Abstract}

This article analyses Koselleck's relation to the socio-political categories emerging with the new temporality in the last decades - particularly the notion of negative memory. Although Koselleck was recognized as a theorist of Modernity and is a reference thinker for many critics and interpreters of this new chronotope following the crisis of modernity, he does not fit into the new chronotope. After reviewing some interpretations of the present time, such as Hartog's presentism, German compensation theory, Gumbrecht's extended present and Assmann's politics of memory, Koselleck's late texts on negative memory are analysed. As he insisted on opposing memory to history, he had a critical stance to the present. Ironically, his courage in confronting recent German history brings him away from 
Monográfico | Koselleck, la memoria y la historia. Sobre la dificultad de entender el tiempo presente

le hace más difícil acercarse a las nuevas culturas de la memoria, y le enreda en nuevas paradojas. Con ello, también, le limitan a la hora de interpretar y comprender este nuevo cronotopo.

\section{Palabras clave}

Koselleck, memoria, historia, identidad colectiva, experiencia, Aleida Assmann, teoría de la compensación, Gumbrecht, lento presente. recent politics of memory. For this reason also, he was unable to interpret and understand the new chronotope.

\section{Keywords}

Koselleck, memory, history, collective identity, experience, Aleida Assmann, compensation theory, Gumbrecht, extended present. 


\section{Introducción: interpretar el presente}

Reinhart Koselleck se ganó un merecido prestigio como intérprete de la Modernidad, aparte del que ya tenía como historiador conceptual y editor de los Geschichtliche Grundbegriffe. Sin embargo, ese segundo reconocimiento se hizo patente más bien en los años noventa, cuando el mundo moderno que él había enseñado a analizar como una modalidad precisa de tiempo histórico era ya un mundo distinto; o cuando menos, había adoptado una temporalidad distinta, que producía, y todavía produce, desconcierto en quienes se habían formado en la modernidad clásica. ${ }^{1}$ Gran parte de lo que Koselleck escribió durante los dos últimos decenios de su vida², entre 1980 y 2006, era también una confrontación con esa nueva temporalidad, con ese ritmo de las cosas que había dejado de adaptarse a los compases del progreso histórico. De hecho, su voz ha tenido un peso y una personalidad propias en los debates sobre muchas de las cuestiones relevantes de esos años que siguen pendientes todavía hoy, como la memoria, la aceleración, la exacerbación del presente, la ausencia de perspectivas de futuro o la pérdida del sentido histórico. Si, en los años setenta, los historiadores sociales todavía podían aventurar que la historia conceptual de Koselleck era un callejón sin salida cuyos ecos se apagarían pronto, ${ }^{3}$ ha resultado al final que muchos de los intérpretes más destacados y prolíficos de este período postclásico de la modernidad, especialmente en el mundo de habla alemana, tienen a Koselleck como referencia. Autores crecidos y formados ya en la postguerra mundial, como Odo Marquard, Hans Ulrich Gumbrecht, Aleida Assmann o, ya en el mundo francés, François Hartog escriben desde las categorías de la temporalidad diseñadas por Koselleck -aunque a veces críticamente hacia él- para ofrecer los diagnósticos que más resonancia pública y académica han tenido

1. Entenderé por «modernidad clásica», siguiendo a H. Rosa, Beschleunigung und Entfremdung, Frankfurt a. M., 2011, el período que va de 1850 a 1970. Sobre esta periodización, con más detalle, ver la siguiente sección.

2. Me referiré sobre todo a los textos recopilados por Carsten Dutt en Vom Sinn und Unsinn der Geschichte, Frankfurt a. M., 2014. Dejo de lado los importantes estudios sobre iconología política, recopilados, junto a algunos de los anteriores, por Faustino Oncina en Modernidad, culto a la muerte y memoria nacional, 2a ed., Madrid, 2020.

3. H.-U. Wehler, "Geschichtswissenschaft heute", en J. Habermas (Dir.) Stichworte zur geistigen Situation der Zeit, Bd. 2, 1979, 725. 
acerca de las transformaciones sociales y culturales del mundo, o del mundo occidental, en los últimos decenios del siglo XX y los primeros del XXI. ${ }^{4}$

Hay aquí una paradoja. Los intérpretes del mundo contemporáneo a los que me he referido trabajan con las categorías y las herramientas conceptuales de un mundo, el moderno clásico, del que perciben que ya no es el suyo, aquel en que se formaron y crecieron; un mundo al que, unos para bien y otros para mal, dan por acabado. Posiblemente, esa paradoja es inherente a cualquier tratamiento que se haga del tiempo y del presente. Pues siempre nos vemos obligados a entender cada presente con las categorías recibidas del pasado inmediatamente anterior, del que voluntaria o involuntariamente nos hemos despedido: no disponemos más que de unas herramientas de las que percibimos que ya no valen. Es preciso inventar unas nuevas.

En este ensayo no trataré de esas nuevas herramientas conceptuales, o de las nuevas categorías que se estén ensayando. Me centraré más bien en cómo Koselleck se enfrenta a esta temporalidad que ya no es la moderna-clásica, sino la de los últimos cuarenta o cincuenta años, cuando las categorías metahistóricas que él desarrolló a partir de los Geschichtliche Grundbegriffe y de Vergangene Zukunft, sobre todo la de expectativa y experiencia, han perdido su evidencia anterior en la nueva actualidad emergida en el cambio de siglo XX al XXI. Para este análisis, revisaré brevemente la dinámica de historia y Modernidad según Koselleck, la compararé con los autores que he mencionado anteriormente, y que lo toman como referencia, en tanto que son intérpretes reconocidos de este presente actual. Además, de entre los temas relevantes de este presente, dedicaré una atención especial al problema del recuerdo, la memoria y la experiencia, tan centrales hoy día, y a los que Koselleck dedicó una parte importante de sus últimos textos.

\section{Excurso onomasiológico: los nombres de las épocas}

Toda vez que voy a tratar de temporalidad y temporalización, conviene hacer antes una aclaración terminológica. En las líneas introductorias que preceden, he mantenido una deliberada ambigüedad sobre los tiempos o épocas a los que me estoy refiriendo y sobre sus denominaciones, si bien, de modo global, he estado distinguiendo una modernidad clásica y un periodo de tiempo que abarca los últimos decenios del siglo XX y los dos primeros del XXI. Ciertamente, nada es menos inocente que bautizar una época. Además, fue una de las aportaciones de Koselleck mostrar que una de las claves de la Modernidad es la capacidad de ésta para, no solo bautizar las épocas, sino cualificarlas como un tiempo histórico específico $^{5}$, distinto intrínsecamente de los otros. Precisamente por eso, desde esa sensibilidad moderna para el tiempo, y sobre todo para el presente, registramos, como muy tarde desde

4. Podrían añadirse más autores a esta lista, desde Paul Ricoeur en sus estudios sobre La memoria, la historia, el olvido a Zygmunt Baumann, Wasted Lifes... o el ya mencionado Harmut Rosa.

5. Sobre esto, especialmente, los dos primeros ensayos de Vergangene Zukunft. Zur Semantik geschichtlicher Zeiten, Frankfurt a. M., 1977. 
los años ochenta, un cambio social y cultural respecto los ritmos comúnmente aceptados como modernos. Si ese cambio significa un final del tiempo anterior, una ruptura hacia un tiempo específico nuevo, o bien se trata de una intensificación de la propia actitud moderna, que se hace todavía más reflexiva, es la parte final del argumento de las discusiones sobre el presente, de manera que la postura que se tome determina la denominación que se elija. Y dicha denominación puede ser objeto de una batalla intelectual. Se ha hablado, por ello, en diferentes fases, y con argumentos contrapuestos, de "postmodernidad», de "posthistoria», del «final de la historia», de «modernidad reflexiva», de «metamodernidad», de "presente extendido» $\mathrm{o}$ "presente ancho", etc. Estas denominaciones, a la vez que referencias, constituyen descripciones más o menos definidas de lo que ocurre o ha venido ocurriendo en esos años. Optar por una de ellas supone comprometerse con una descripción e, inevitablemente, con una política y unas fuerzas concretas constitutivas del presente: el nombre funciona también como un performativo. Más abajo, discutiré algunas de esas posturas.

Koselleck también percibió el cambio. Era demasiado historiador para admitir el fin de la historia, o la posthistoria; pero tenía un instinto teórico lo bastante fuerte como para no darse cuenta de que las categorías modernas que él había descrito en los años setenta -particularmente, las de experiencia y expectativa- ya no funcionaban como lo habían hecho en los dos siglos anteriores. En todo caso, no se propuso inventar un nuevo nombre para una nueva época. Nombrar una época es un modo de darla por finiquitada, decía Ivan Illich. La ausencia de un nombre definitivo es síntoma, cuando menos, de que este presente todavía está inacabado. Así, al menos, lo consideraré aquí de partida, y, en lo que sigue de este texto, evitando dar nombres determinados, me voy a atener a la periodización siguiente:

1. Una «modernidad temprana», que abarca desde el renacimiento a la Ilustración, o hasta la divisoria de tiempos que Koselleck llamaba el Sattelzeit.

2. Una «modernidad clásica», que corresponde al siglo XIX y la primera mitad del XX cuando menos, aunque de modo efectivo sigue resonando en los llamados «treinta gloriosos» años de la postguerra mundial, hasta los años setenta.

3. Los últimos cincuenta años, a partir de 1980, en los que se ha registrado el cambio cultural, político, social y tecnológico al que me he referido. Algunos registrarían antes los inicios de ese cambio, otros lo asociarían al ascenso y hegemonía del llamado Neoliberalismo. Para evitar comprometerme con cualquiera de las denominaciones mencionadas, hablaré de esta época neutralmente como «los últimos cuarenta años», «la actualidad»o, en ocasiones, «modernidad postclásica».

Es de este último período del que tratamos. De la paradoja de diagnosticar el presente y de cómo Koselleck se enfrenta, y en parte sucumbe, a esa paradoja. 


\section{Koselleck y la crisis de los últimos cincuenta años}

Como decía más arriba, interpretar el presente conlleva la paradoja de tener que hacerlo con las herramientas conceptuales de un tiempo inmediato anterior que se ve como ya pasado. Esa situación paradójica puede advertirse en el propio Koselleck, cuando se confronta el teórico maduro con el historiador joven. Sin duda, hay una continuidad en el rigor y en el estilo; no se advierten en su trayectoria los giros bruscos que sí se dieron en otros pensadores de su generación. Al comienzo está el joven que ha sido un soldado convencido de la Wehrmacht y que vuelve de la experiencia bélica y del cautiverio como prisionero de guerra de los soviéticos, para escribir, explícitamente inspirado por Carl Schmitt, una acerba crítica de la Ilustración: Crítica y crisis, con el indicativo subtítulo de «Sobre la patogénesis del mundo burgués». ${ }^{6}$ En su período de madurez, tras el escrito de habilitación sobre el Allgemeine Preußische Landrecht, están los decenios de trabajo en la edición de los Geschichtliche Grundbegriffe, así como la monografía Vergangene Zukunft. Es aquí donde esboza de manera más articulada su concepción del mundo moderno como una «semántica de los tiempos históricos»: sobre todo, la investigación sobre el nacimiento de un lenguaje sociopolítico nuevo a partir de la llamada Sattelzeit, ese tiempo divisorio que va de 1750 a 1830. Los escritos de los años ochenta y noventa, sin embargo, abandonan la práctica de la historia conceptual para entrar de lleno en el tema por excelencia de su obra, «una teoría de las estructuras temporales de las experiencias humanas, de sus historias y de sus relatos» ${ }^{7}$, lo que implica una confrontación con su propio presente: trata ahora de dar cuenta, no sólo como historiador, sino como intelectual que participa activamente en el debate público alemán, de cuestiones como la aceleración social, las políticas de la memoria y del recuerdo, el surgimiento de las identidades colectivas como agentes históricos, la confrontación entre historia y memoria. Aborda estas cuestiones con independencia intelectual. Sus posiciones no coinciden con las del bando liberal conservador al que se le solía adscribir a la ligera ${ }^{8}$; tampoco se alinea con la izquierda progresista bundesrepublicana agrupada en torno a la teoría crítica. Sin embargo, nunca queda por detrás de ella en la insistencia y crudeza con que vuelve sobre la catástrofe de 1933-45, la acribia con la que recorre y enumera sin excusas los crímenes alemanes y, por ende, hace explícita la profundidad de la culpa de su país. En eso, se distingue de otros intelectuales conservadores ligados a la historia conceptual, que suelen pasar de puntillas o con excusas sobre el tema, como Lübbe, en su generación o como Marquard y Gumbrecht en las generaciones siguientes. En este sentido, sobre todo, lo llamativo es que la trayectoria de Koselleck es paralela a la de la actitud dominante en la propia República Federal Alemana, que en los años cincuenta mantenía un silencio -hoy

6. R. Koselleck Kritik und Krise. Zur Pathogene der Moderne Welt, Frankfurt, 1973. La primera edición es de 1955. Hay traducción española, Crítica y crisis. Madrid, 2009.

7. F. Oncina, introducción a la segunda edición de Modernidad, op. cit., LIV.

8. Véanse, en particular, los esclarecedores hallazgos de Faustino Oncina sobre la posición de Koselleck durante la Historikerstreit, mucho más activa de lo que se ha creído siempre, y muy distante del Neoconservadurismo alemán. Modernidad... op. cit., XXVI-LII. 
diríamos que escandaloso- sobre el inmediato pasado nacionalsocialista -también lo hizo él en Crítica y crisis-, para volver masivamente sobre ese pasado en los años noventa, reconociendo y rememorando los crímenes y el genocidio en casi todas las esferas institucionales y culturales. En eso, Koselleck hizo el mismo movimiento, del silencio al recuerdo, que toda su generación y que la sociedad alemana occidental en su conjunto: un movimiento por el que se hacía cada vez más consciente, o cada vez más explícito para sí mismo y para el público, el grave peso del siniestro pasado alemán.

Sin embargo, a pesar de esta sintonía con la sensibilidad histórica y moral de la sociedad en la que vivió y trabajó, no estaba cómodo con las nociones que se habían vuelto dominantes en ese nuevo tiempo histórico en el que la postguerra mundial había desembocado. No es su caso, ciertamente, el de una nostalgia del progreso, o de los tiempos en que la visión progresista de la historia se daba por sentada: esa nostalgia que todavía podía percibirse en muchos representantes de la izquierda marxista y del liberalismo que se revolvían contra los discursos de la postmodernidad o del fin de las grandes narraciones. Koselleck era un escéptico. Su oficio de historiador, junto a la experiencia de haber participado y sufrido la derrota en la mayor catástrofe del siglo, le alejaban mucho del optimismo progresista de la izquierda; pero también le hacían mirar con desconfianza el ascenso y transformación de los nuevos conceptos que, durante los últimos cincuenta años, parecían romper las coordenadas del mundo moderno. En el lenguaje sociopolítico que surge en los ochenta, y alcanza su apogeo en el cambio de milenio, pasan a primer plano, con una semántica profundamente transformada, a menudo en conflicto con los conceptos históricos fundamentales de la Modernidad, nociones como memoria, recuerdo, identidad (especialmente la identidad colectiva) o experiencia. Los discursos sociopolíticos, también estéticos, de estos años se han nutrido de ellos y los han ido expandiendo hasta hoy. Koselleck, en cambio, mantuvo una distancia crítica hacia esas nociones. En este sentido, se hallaba mucho más escindido de esta nueva actualidad que quienes, desde una crítica con pretensiones radicales, recurren a la memoria o la identidad para interpretarla e intervenir en ella.

Sin embargo, en cierto sentido, si se toman las categorías metahistóricas que Koselleck había desarrollado para interpretar la Modernidad, esta nueva actualidad no debería resultar sorprendente. La explicación que él mismo había propuesto -ya en los años setenta, con Futuro pasado- para la dinámica temporal del mundo moderno sugería que la Modernidad tendría que desembocar en algo parecido a lo que parecía registrarse de modo unánime en los años noventa: la aceleración del tiempo, el desmantelamiento del campo de experiencias y la difuminación del horizonte de expectativas. Pues, al menos si se leen despacio sus textos sobre la aceleración de la historia y el último ensayo de Futuro pasado, ${ }^{9}$ parece seguirse que la Modernidad implicaba una variación profunda de una de las estructuras antropológicas fundamentales de la temporalidad humana; y también que

9. R. Koselleck, “Erfahrungsfeld und Erwartungshorizon. Über zwei metahistorischen Kategorien”, en Vergangene... op. cit. 
la profundidad de esa variación terminaba por ser una ruptura que dejaba atrás a la Modernidad misma. Veamos este punto más detenidamente.

La estructura de la temporalidad humana consiste en que los seres humanos comprenden el mundo y conducen su acción entre un campo de experiencias pasadas y un horizonte de expectativas respecto al futuro. Es esta una constante antropológica en la que se encuentra una condición trascendental de la posibilidad de todas las historias en cualquier sociedad humana. Sobre el campo de experiencias pasadas se les abre a los seres humanos, cualquiera que sea su forma de organización social, un horizonte de expectativas en el que se dibuja lo que les cabe esperar y lo que puede hacer. ${ }^{10}$ Lo específico de la modernidad occidental es que esa relación entre el campo y el horizonte se hace dinámica, porque el pasado deja de ser el terreno firme e incuestionado sobre el que asentarse y enraizarse. Antes bien, porque el mundo se transforma, o porque la historia deja de ser la maestra de la vida, la experiencia deja de ser el depósito de reserva donde se guardan los hechos e historias del pasado, y desde el que orientar la acción. En lugar de ello, la experiencia pasa a entenderse, dialécticamente, como la transformación que experimentan los sujetos en su interacción con el mundo, especialmente en los momentos críticos en lo que se rompen las expectativas ${ }^{11}$ : es una transformación de los sujetos y del mundo mismo. El resultado de una experiencia no es la confirmación de un pasado anterior, sino la reconfiguración del campo de las experiencias pasadas y, consecuentemente, de las expectativas futuras. Hacer una experiencia es, sobre todo, reconfigurarse a sí mismo y reelaborar las propias expectativas. El presente y el pasado han dejado de coincidir, o se han convertido en tiempos específicamente diferentes - por lo que el pasado ya no puede enseñarnos nada o, como se lamentaba Tocqueville: «la luz del pasado ya no ilumina el porvenir». Para los modernos, el presente es una especie de permanente desencuentro provisional, un momento de extrañamiento que sólo se resuelve cuando el pasado y el futuro pueden reenlazarse de algún modo. Para ello, el presente debe reescribir el pasado, y acomodarlo al nuevo horizonte de expectativas. A partir del Sattelzeit, cada presente, cada crisis del presente, se resuelve mirando al pasado retrospectiva y selectivamente -como conciencia histórica- de modo que se encuentre algún hilo con él que prolongar hacia el futuro. Se organiza selectivamente el pasado para construir el futuro.

Koselleck mostró precisamente que la noción de progreso -y su transformación en categoría temporal a partir del Sattelzeit- es el instrumento que tuvieron los modernos para tender ese hilo: aunque las experiencias y las expectativas fueran modificándose dramáticamente, la idea de progreso y de una historia universal que le acompaña permitía darle cierta continuidad, aparente o real, a la temporalidad moderna. Esta se tejía en la indeterminación del futuro, la revisabilidad permanente del pasado y la provisionalidad del

10. Véase, en castellano, el homenaje a Gadamer, y discusión con él, en H.Gadamer y R. Koselleck, Historia y hermenéutica, Barcelona, 1997.

11. Veáse A. Gomez Ramos, "La inmediatez de la crisis y la experiencia del tiempo", en L. Cadahia y G. Velasco (Dir.) Normalidad de la crisis. Crisis de la normalidad, Madrid, 2013, 101-122. 
presente. ${ }^{12}$ El progreso, el relato del progreso, permitió articular esos tres focos a partir del siglo XVIII. Toda la Modernidad clásica, ya fuera en la perspectiva liberal o en la marxista, se comprendía desde esa articulación.

Ahora bien, este equilibrio entre experiencias y expectativas, entre el campo y el horizonte, no podía sostenerse de manera constante. Lo que los modernos perciben con una fuerza creciente es que el campo de experiencias y el horizonte de expectativas se van alejando uno de otro como dos galaxias distintas, y los esfuerzos por rearticularlos se empiezan a hacer desesperados. Durante la modernidad clásica, reestructurando continuamente el tiempo entre un campo de experiencias y un horizonte de expectativas, el presente, al decir de Luhmann, «se había especializado en la integración temporal», integración que se realizaba por medio de eso que hemos llamado experiencia. Pero lo que se percibe al final de la modernidad clásica es que «desgraciadamente, el presente ya no tiene tiempo para hacer su tarea.» ${ }^{13}$

Koselleck sabía que esta aceleración que tanto vértigo produce en los contemporáneos era la marca de la Modernidad desde sus inicios, y podía recurrir a Goethe para hablar de una modernidad «velociferina»: un invento del diablo. En algo de eso se apoyaba Harmuth Rosa para proponer la aceleración histórica y social como paradigma explicativo de la Modernidad. ${ }^{14}$ Lo que las personas del temprano siglo XIX experimentaban dramáticamente es que las expectativas habían dejado de corresponderse con las experiencias a causa de la rapidez de los cambios históricos. La aceleración formaba parte del esquema moderno, a la vez que era una transposición secularizada de un viejo gesto teológico ante el final de los tiempos. ${ }^{15}$ Pero la secularización era algo más que una traducción de las viejas metáforas a un lenguaje sin términos religiosos. Pues lo que en 1800 era una sensación subjetiva de los individuos, que aún podía llegar a articularse gracias a nociones como progreso e historia -nociones que quizá podían aun considerarse como teología secularizada- ${ }^{16}$, en los años postreros del siglo $\mathrm{XX}$ y, desde luego, en estos primeros del siglo XXI se manifestó de manera general como la desarticulación definitiva del campo de experiencias y el horizonte de expectativas. Uno y otro se habían alejado tanto que los habitantes del año 2000 se sentían incapaces de producir visiones mayoritariamente aceptadas de un futuro distinto y de profundizar en el pasado histórico. El tiempo se había salido de su quicio.

Koselleck, sin embargo, era demasiado historiador para lanzarse a hacer un diagnóstico global del presente. Podía constatar, a lo sumo, como hace al final del texto sobre «Aceleración, prognosis y secularización», que lo que se percibe como una extraordinaria aceleración social encaja dentro de la propia aceleración de la historia humana cuando se considera esta

12. C. Ireland, The Subaltern Appeal to Experience, Self-Identity, Late Modernity and the Politics of Immdiacy, Toronto, 2004, 70.

13. L. Niklas, “The Future Cannot Begin: Temporal Structures in Modern Society”, en Social Research, 43, 1976, 146.

14. H. Rosa, Beschleunigung, op. cit.

15. Koselleck, Aceleración, prognosis y secularización. Valencia, 2001.

16. Así en Löwith, uno de los maestros de Koselleck, cuyo Meaning in History él contribuyó a publicar en alemán. 
a gran escala. La modernidad encaja dentro de un esquema más general en el que los tiempos se van acortando. De los cientos de miles de años de cazadores recolectores a los miles de años de agricultura, a los cientos de años de imprenta e industrialización y las decenas sociedad digital, etc. El gesto en que deja caer esta observación es más el de un observador fuera del tiempo que el de alguien que diagnostica el presente. ${ }^{17}$

Quienes sí han hecho diagnósticos de los últimos cincuenta años, sin embargo, han tenido muy presente estas categorías koselleckianas explicativas de la Modernidad. Al menos en el ámbito continental, germánico, se ha asumido de modo mayoritario una descripción del mundo moderno ligada a una concepción de la Historia en la que se perciben la profundidad temporal de las distintas épocas, que quedan organizadas en una idea de historia universal regida, con diversas modulaciones, por el hilo conductor del progreso, y proyectada hacía un horizonte previsto, planeado o deseado del futuro. De hecho, si por algo se caracterizan los diagnósticos y descripciones filosófico-históricos de los últimos decenios es por certificar el final de la conciencia histórica en su figura moderna; esto es, la pérdida tanto del sentido histórico como de la perspectiva de futuro, acompañada del predominio del presente y del desvanecimiento de la posibilidad de una experiencia histórica. Los juicios que resultan de este diagnóstico son diversos: aparte del rechazo crítico que lamenta el presentismo y la pérdida de sentido histórico (Hartog), que se apoya fuertemente en Koselleck, están la celebración de una nueva temporalidad postmoderna, o posthistórica, en la que lo histórico funciona como compensación frente a la aceleración moderna (Marquard, Lübbe, la escuela de Ritter), la búsqueda de nuevas formas de experiencia como presencia para un presente que se ha extendido hacia el pasado y el futuro (Gumbrecht), o la revisión del programa moderno para «repararlo» y readaptarlo a las demandas de este presente que, más que negar la modernidad, la somete a revisión (Assmann) ${ }^{18}$ Dado que las cuatro figuras mencionadas toman a Koselleck como referencia, en la sección siguiente vamos a hacer un repaso de sus planteamientos. Encontraremos en ellas varias nociones claves en la actualidad -sobre todo, memoria e identidad- que, en una última sección, contrastaremos con los últimos escritos de Koselleck.

\section{Diagnósticos de los últimos cuarenta años}

El francés François Hartog emitía ya en 1998 un juicio negativo sobre lo que él consideraba el nuevo «régimen de historicidad» adoptado por las sociedades occidentales a partir de los

17. Véase el final del ensayo "Acortamiento del tiempo y aceleración", en Koselleck, Aceleración, prognosis y secularización..., op.cit., así como la introducción de Faustino Oncina.

18. Ciertamente, hay muchas otras interpretaciones de esta época, con sus denominaciones correspondientes. Está la modernidad reflexiva de Anthony Giddens, la modernidad líquida de Zygmunt Baumann, las diferentes variantes de postmodernidad o modernidad singular de Fredrick Jameson, entre otras. Pero siendo estás de corte más sociológico o culturalista, las cuatro que propongo se hacen explícitamente en clave de tiempo histórico, lo que mueve a confrontarlas con la época de Koselleck. 
años setenta. Si este régimen determina «los modos en que una sociedad se acerca a su pasado y reflexiona sobre él», y por tanto, «las modalidades de autoconciencia que una sociedad adopta en su construcción del tiempo y sus percepciones», ${ }^{19}$ esas modalidades habían cambiado drásticamente a partir de los acontecimientos del 68, y se había agudizado en los noventa. A pesar de la continuidad política e institucional que existe con las sociedades occidentales de postguerra - una continuidad afirmada, además, por la caída del mundo soviético y la extensión general de la democracia parlamentaria- la percepción del tiempo y de la historia -entre las poblaciones tanto como entre los académicos- se había transformado, si es que no arruinado. Hartog localiza ese cambio en lo que él llama la pérdida de sentido histórico en favor de un "presentismo» donde se produce la «máxima distancia entre el campo de experiencias y el horizonte de expectativas, una distancia que linda la ruptura, de modo que el engendramiento de tiempo histórico pareciera suspendido». ${ }^{20}$ Este presentismo, refiriéndolo todo al momento actual, desestructura el conocimiento y experiencia de la historia elaborado por la historiografía anteriormente, a la vez que vacía el futuro de contenido. Ciertamente, presentismos, momentos en los que toda luz viene únicamente del momento presente, ha habido muchos en la cultura y la sociedad. Hartog menciona a Plutarco, a Marco Aurelio, a Goethe o a los existencialismos; todos ellos con distinto valor y sentido. Los modernos mismos, recuerda él, aspiraban a esa especie de presente absoluto que era el objetivo de su arquetipo Fausto cuando exclamaba «Ahora el presente no mira hacia adelante ni hacia atrás. Sólo el presente es nuestra dicha $»^{21}$. Pero eso -que a posteriori se revela como una mera ilusión- es distinto del presentismo que habría aparecido primero bajo el nombre de postmodernidad. Este último se mira a sí mismo con desconcierto, sin plenitud, y «no deja de mirar hacia adelante y hacia atrás, pero sin salir del presente del cual se ha hecho su único horizonte.» ${ }^{22}$ Paradójicamente, esa mirada hacia atrás no es la del historiador -o al menos, no es la del historiador moderno-, que trata de explicar y estructurar el pasado con vistas a dar sentido al presente y al futuro, sino que es una mirada ávida de historización, de catalogación y registro exhaustivo del pasado. Un ejemplo claro y potente es el proyecto de la Fundación Spielberg, consistente en recoger y almacenar «todos los testimonios de todos los sobrevivientes de los campos nazis, para tener en directo (on-line) la verdadera historia de la deportación a través de la voz misma de las víctimas.» ${ }^{23} \mathrm{El}$ desarrollo tecnológico promete un almacenar materialmente de manera ilimitada todo el pasado, de modo que se pueda tener un acceso directo a él, en el presente y como si fuera presente. No sólo con la historia del Holocausto, como intenta Spielberg, sino con la explosión de instituciones museísticas y de patrimonio que aspiran a conservar el pasado en su totalidad y ofrecerlo permanentemente para su consumo pre-

19. F. Hartog, Regímenes de historicidad. Presentismo e historia del tiempo, México, 2007, 106.

20. F. Hartog, Regímenes... op. cit., 40.

21. F. Hartog, Regímenes... op. cit. 236.

22. F. Hartog, Regímenes... op. cit. 236.

23. R. Silva. "Memoria e historia. Entrevista con François Hartog”, en Historia Crítica, 48, 2012, 212. 
sente, a menudo como una reconstrucción ficticia. El llamado patrimonio se refiere a un pasado sin sustancia histórica. Quien queda aquí fuera de juego, se lamenta Hartog, es el historiador, el cual parece más bien «entorpecer el encuentro cara a cara entre el testigo y el espectador.» ${ }^{24} \mathrm{El}$ enorme peso que va adquiriendo la noción y la práctica del patrimonio, que de todos modos había sido siempre una obsesión de los modernos ${ }^{25}$, significa una anulación de la conciencia histórica, al situar todos los elementos del pasado en un mismo plano temporal por el que se mueven las conciencias, ya prácticamente ahistóricas, de los turistas, de los teóricos de la cultura, de académicos y políticos. En ese plano, se pierde la percepción de la profundidad temporal que era el resultado del saber histórico, y para el cual era fundamental el trabajo del historiador. El patrimonio acumulado sustituye al conocimiento histórico, y la historia como ciencia queda en el mismo plano de validez que la memoria y los testimonios de los testigos. Si el régimen de historicidad es «un modo de organizar la experiencia del tiempo, de articular pasado presente y futuro invistiéndolos de sentido» ${ }^{26}$, el nuevo régimen presentista elimina la profundidad temporal moderna en favor de una simultaneidad de los tres tiempos que solo se sostiene desde los intereses y la mirada del presente hacia sí mismo. Patrimonio y memoria, memoria entendida como vivencia directa del pasado a través del patrimonio, sin necesidad la mediación teórica del historiador o del filósofo, son los dos vectores dominantes de la percepción moderna del tiempo, en la que no hay ya ningún lugar para un horizonte del futuro.

Este aumento enorme del pasado en lo cultural, en lo ideológico y también lo económico -la historia convertida en mercancía- merece, en cambio, un juicio mucho más positivo, e incluso encuentra una cierta justificación psicosocial, en todo caso antropológica, en los teóricos alemanes de la compensación ligados a la historia conceptual. «A la vez que la dinámica de los procesos civilizatorios de modernización, va creciendo, de modo complementario, la necesidad de esforzarse por hacer presente el pasado.» ${ }^{27}$ Lo propiamente humano es, al decir de Marquard, el ritardando. La enorme aceleración vital y social con que la modernización somete a los modernos obliga a estos a buscar una compensación en espacios intactos del pasado, aparentemente no afectados por las transformaciones modernas, y no otra cosa es para él el sentido histórico. ${ }^{28} \mathrm{La}$ antropología se rebela contra la aceleración de la historia. El pasado, el patrimonio, lo histórico, ya sea real o inventado, aparece como una magnitud fiable, una especie de "osito de peluche» ${ }^{29}$ al que los estresados habitantes de las ciudades modernas se agarran en un mundo que cambia cada vez más rápido. En una suerte de explicación casi naturalista, resulta que las sociedades modernas se reequilibran y sobreviven porque dispo-

24. R. Silva. "Memoria e historia...”, op. cit., 212.

25. Recuérdese el trabajo clásico de Lowenthal, El pasado es un país extraño, Madrid, 1995.

26. F. Hartog, Regímenes... op. cit., 106.

27. H. Lübbe, "Der verkürzte Aufenthalt in der Gegenwart. Wandlungen des Geschicthsverstäntnisses", en P. Kemper (Dir.) Postmoderne oder der Kampf um die Zukunft, Frankfurt a. M., 1988, 150.

28. O. Marquard, "Universalgeschichte und Multiversalgeschichte”, en Apologie des Zufälligen, Stuttgart, 1996. (trad. en Apología de lo contingente, Valencia, 2001).

29. La irónica expresión es de A. Assmann, Ist die Zeit aus den Fügen, Franfurt a. M., 2013, 238. 
nen de una reserva inmensa de pasado ajeno a los cambios presentes y en los que los sujetos se pueden refugiar, aunque sea los fines de semana y en vacaciones. De ahí el cuidado hacia el patrimonio, el resurgir de las antiguas costumbres y tradiciones, la búsqueda de raíces en una supuesta identidad anterior... no es una pérdida de la conciencia histórica, ni hay que lamentar su carácter a menudo superficial y ficticio: esa omnipresencia del pasado es un instrumento de equilibro, un ancla que impide que la Modernidad lo deshaga todo en el aire. De hecho, afirman, y a menudo creen encontrar pruebas tangibles de ello, las sociedades que saben reafirmar y cuidar su patrimonio y su historia son las que mejor y más establemente llevan e impulsan la aceleración moderna.

Ciertamente, Joachim Ritter había formulado originalmente la noción de compensación como una crítica al historicismo. El joven Ritter, todavía marxista, veía en la conciencia histórica, en el mundo histórico de Dilthey y toda su generación «la función compensatoria que desarrolla la persona culta para su inefectividad histórica $»^{30}$, esto es, para su impotencia política. Y, de paso, esta conciencia histórica conservaba una actitud religiosa en un mundo secularizado. El Ritter maduro -o el Ritter que ha pasado por la militancia nazi y la conversión a la democracia tras la derrota- en cuya escuela se forman los teóricos de la compensación (Marquard, Lübbe), reorienta esta explicación: efectivamente la historia tiene una función compensatoria, pero ya no para con la impotencia política, sino para los desarreglos sociales y psicológicos resultantes de la aceleración moderna. Para una postura crítica, no sería difícil ver que el efecto perturbador de esos desarreglos remite de nuevo a una impotencia política, o una inefectividad histórica: la historia convertida en refugio. Tampoco es difícil maliciar, como ha hecho Assmann, ${ }^{31}$ que, además, en el caso de la postguerra alemana, esa revalorización compensatoria del pasado tenía igualmente la función de un recuerdo encubridor (una Deckerinnerung freudiana), que evitaba hablar del nacionalsocialismo y, desde luego, de las implicaciones juveniles que tuvieron con él sus protagonistas. Pero, lejos de la crítica o del examen de la propia historia, los teóricos de la compensación entienden ésta de manera meramente funcionalista. Las sociedades modernas resisten a la aceleración porque tienen -o resisten si son capaces de mantener- la historia y el pasado como refugio a su disposición. Por eso, no son los recuerdos traumáticos los que aparecen con una función compensatoria, sino la historia anterior, la historia tranquilizadora, a la que se accede, ya no desde la cúspide de los tiempos -como era el caso de Schiller-, ni desde una historia en proceso, cuya perspectiva va cambiando, sino desde un "presente encogido» de Lübbe en el que cambia todo sin que, en realidad, haya cambiado nada. Es, sobre todo, un espacio donde multitud de historias se ofrecen al consumidor como alternativas coloridas a la historia universal, tal como alegremente lo describe Marquard ${ }^{32}$. Esas historias, reinterpretadas además como diversidad cultural, se ponen a disposición de los habitantes de un presente ya desligado del pasado y del futuro -bautizado, de hecho, durante un tiempo, como postmoderno- $y$ ofrecen, a la vez,

30. Véase E. Müller y F. Schmieder, Begriffsgeschichte und historische Semantik. Frankfurt a. M., 2016, 118.

31. A. Assmann, Ist die Zeit... op.cit., 209ss

32. O. Marquard, “Multiversal Geschichte..., op. cit. 
identidad y experiencia: al menos, una experiencia estable del mundo que la modernidad acelerada amenaza continuamente con robar. «La tarea de la historiografía profesional -concluye Marquard- es preparar y poner a disposición conocimientos históricos que permitan hacerse presente la identidad propia y la extraña» ${ }^{33}$

Precisamente una renovada noción de experiencia es lo que propone Hans-Ulrich Gumbrecht, que se curtió en el trabajo de los Geschichtliche Grundbegriffe para dar luego por finiquitada la historia conceptual. ${ }^{34}$ Pero él afina respecto a los teóricos de la compensación. De hecho, aunque éstos se refieren explícitamente a la postmodernidad, su propuesta de contrapesar progreso e historia vale tanto para esta época como para la Inglaterra victoriana. En cambio, Gumbrecht identifica explícitamente este período de los últimos treinta o cuarenta años con el final del cronotopo moderno descrito por Koselleck. Le da, además, un nombre al nuevo cronotopo: la breite Gegenwart o el presente extendido. Desde los años sesenta, no se registra realmente ninguna novedad cultural o social, y las sociedades occidentales han renunciado a plantearse visiones de futuro, mientras el pasado se les ofrece exhaustivamente en toda su variedad y multiplicidad gracias, desde luego, a la tecnología y a la ciencia de la historia. Pocos autores han descrito con más convicción este tiempo sin futuro ni pasado, un «tiempo que se ralentiza» a escala global, que no produce ni cultural, ni intelectualmente nada nuevo, a pesar de la aceleración que se experimenta en la vida técnica y social. No repasaré ahora los argumentos de Gumbrecht para afirmar que todo Occidente se encuentra instalado en este lento presente ${ }^{35}$, ni la melancolía con que impregna su mirada hacia un tiempo que, de por sí, no aparece como melancólico, sino más bien -y esta es su crítica irónica-, satisfecho de sí mismo. Ya hemos constatado al principio que el cronotopo moderno descrito por Koselleck se ha modificado profundamente. Lo interesante de la aportación de Gumbrecht es la, por así decirlo, terapia que él propone para la melancolía de estos tiempos estancados, a saber: una forma renovada de experiencia que él denomina presencia, la producción y percepción de presencia. Pues lo que se busca en las vivencias del pasado histórico -en el auge de la novela histórica, en los parques temáticos, en la imitación espuria de formas antiguas de vida- no es una compensación a la aceleración, sino la presencia, el contacto directo con una realidad que un mundo hiperartificial y la exacerbación de la hermenéutica habían secuestrado. El exceso de interpretación en las ciencias del espíritu, casi de forma paralela a la construcción de un mundo hipertecnificado, se ha interpuesto entre los sujetos y la realidad. El remedio, o la terapia, es la producción de presencia, la renuncia a la obsesión moderna por el sentido y el significado para situarse más acá de la hermenéutica, en la materialidad de los textos, del puro ser de las $\operatorname{cosas}{ }^{36} \mathrm{El}$ presente extendido pide presencia, y esa presencia no es, para Gumbrecht, sólo la de la ex-

33. O. Marquard, "Unvermeidlichkeit der Geisteswissenschaften", en Apologie... op.cit., 98.

34. H.U. Gumbrecht, Dimensionen und Grenzen der Begriffsgeschichte. Suttgart, 2006.

35. H.U. Gumbrecht, Lento presente, Madrid, 2010. La versión alemana, ligeramente distinta, es Unsere breite Gegenwart, Frankfurt a. M., 2010.

36. H.U. Gumbrecht, Production of Presence, What Meaning Cannot Convey, Stanford, 2003. 
periencia histórica, sino una entrega quietista al momento presente que se desentiende del futuro y da el pasado, sobre todo el pasado moderno, por despedido.

Frente a este quietismo del tiempo se revuelve otra antigua alumna de Koselleck. El tiempo, dice Aleida Assmann, no se ha salido de sus goznes, como le gusta repetir a Gumbrecht y Hartog para describir el descarrilamiento del cronotopo moderno. Tampoco es un discurrir funcionalizado de la Modernidad entre las aceleraciones tecnológicas y las compensaciones proporcionadas por las disciplinas del espíritu, particularmente las históricas. Ciertamente, la dinámica de campo de experiencias y horizonte de expectativas ya no se da como Koselleck la había descrito al analizar la semántica histórica del vocabulario socio-político en los siglos XIX y XX. De hecho, desde los años ochenta, en estos últimos cuarenta años, el vocabulario es otro. Han surgido nuevos conceptos que antes estaban velados: sobre todo, la memoria, la cultura, la identidad, y estos conceptos han revolucionado de manera inesperada la discusión social y política. Pero no determinan un giro epocal, ni suponen la despedida de una Modernidad ya anticuada. Señalan, sí, fracturas y vacíos en el proyecto moderno que de pronto se hacen inaceptables y dolorosos. Se presentan por ello estos conceptos resurgidos, no como esbozos de futuro, sino como reclamaciones y demandas: hay más identidades posibles que la construcción de la subjetividad racional concebida por el proyecto moderno, las culturas en las que los individuos se reconocen y realizan pueden haberse visto precisamente heridas por él, y la memoria y el recuerdo, sobre todo, muestran que el pasado no es un calmante con efectos compensatorios, como pretendería Marquard, sino una herida abierta que requiere ser atendida. Memoria, identidad y recuerdo son síntomas de que, ciertamente, el régimen de temporalidad se modifica. Desde hace cuarenta años, las disputas sociopolíticas no tienen ya lugar ya en torno a conceptos de la modernidad clásica como libertad y progreso; sino que pugnan por las diversas identidades culturales y por las posibilidades de reparación de los traumas del pasado reciente o incluso remoto.

Esta nueva tonalidad del debate social, que los teóricos de la compensación o el propio Gumbrecht ignoran y que lamentan tanto Hartog (a propósito del patrimonio) como los progresistas de viejo cuño, no ha sacado al tiempo de sus goznes, juzga Assmann. Señala, sí rotos y fracturas graves en el proyecto moderno, pero reclama por eso "arreglos en este proyecto» que deben realizarse, además, desde el espíritu del proyecto moderno mismo. ${ }^{37} \mathrm{La}$ historia moderna, ciertamente, pasa por una crisis y ha entrado en un nuevo estadio que pide profundizar el impulso moderno original, de modo que «ha renunciado a una parte de su arrogancia, ha limado sus diferencias más ásperas respecto a otras culturas y ha desarrollado principios que puedan unirla a otras culturas. ${ }^{38}$ En este optimismo revisionista de Assmann juegan un papel decisivo la cultura y las políticas de la memoria que, a su juicio, están llamadas a determinar la orientación moral y social del futuro. En el reajuste de la Modernidad, la irrupción del pasado no significa una pérdida del futuro ni del sentido histórico, sino que,

37. A. Assmann, Ist die Zeit... op. cit., 281 ss.

38. A. Assmann, Ist die Zeit... op. cit., 246. 
por una «radiografía crítica de la propia historia y de sus fundamentos culturales» ${ }^{39}$ se desarrolla una nueva forma de conciencia histórica que atiende a los traumas del pasado -no a las celebraciones del espíritu, como pretendían el historicismo o la teoría de la compensación-: a una memoria negativa, pues. Desde esa atención, desde la voluntad de no repetir las atrocidades pasadas en el futuro y de mantener presente su recuerdo, se podrán reordenar y hacer refluir las relaciones de pasado, presente y futuro. «De la ruptura civilizatoria han surgido las bases y la responsabilidad de la sociedad civil». ${ }^{40}$ Se debe concebir esto como un reto y un proyecto político que, de cumplirse, invalidaría los diagnósticos de un tiempo estancado, un presente extendido o un tiempo fuera de sus goznes.

No es este el lugar para discutir la propuesta de Assmann, que provee de un fondo teórico a la mayoría de los planteamientos actuales que, cercanos políticamente a la izquierda liberal, no quieren renunciar al proyecto moderno, sino fortalecerlo con la inclusión de nociones inicialmente tan poco modernas como identidad o memoria. La propuesta no está exenta de paradojas y constricciones, y es consciente de ellas. Pero, al cerrar la serie de diagnósticos del tiempo presente que heredan y a la vez ponen en cuestión el legado de Koselleck, el trabajo de Assmann señala los conceptos decisivos de esta actualidad con los que Koselleck se enfrenta en los últimos años de su vida. Y las cuatro posturas que hemos repasado dan juicios contrapuestos sobre ellos, pero los utilizan para construir su diagnóstico. Estos conceptos son los de «recuerdo», «memoria e identidad»y «experiencia».

\section{Koselleck, la memoria negativa y el tiempo actual}

Aleida Assmann empieza dedicándole su libro más polémico sobre la memoria a Koselleck, «que ha marcado como nadie a toda una generación de la postguerra alemana a través de varias disciplinas.» ${ }^{41} \mathrm{Ha}$ aprendido, dice, mucho de él, por más que se mostrara muy crítico con los dos términos claves del libro: la cultura de la memoria y la política de la historia (Erinnerungskultur und Geschichtspolitik). La reivindicación por Assmann de una política de la memoria de los crímenes pasados como fundamento de una sociedad civil democrática futura va más allá de lo que Koselleck estaba dispuesto a admitir, y se sitúa mucho más cerca de su rival Habermas. Koselleck, por su parte, tenía reservas hacia la confianza de los herederos de la teoría crítica en la potencialidad política de una ética anamnética, y más aún hacia la amalgama de memoria, moral y política con la que se argumentan muchas de las actuales políticas del recuerdo. Sobre todo, se rebelaba contra la confusión de historia y memoria, y la relegación de aquella en favor de esta. Coincidía aquí con François Hartog, aunque sus ideas sobre la memoria y el recuerdo político, como veremos enseguida, estaban mucho más desarrolladas.

39. A. Assmann, Ist die Zeit... op. cit., 299.

40. A. Assmann, Ist die Zeit... op. cit. 302.

41. A. Assmann, Der lange Schatten der Vergangenheit. Erinnerungskultur und Geschichtspolitik, Hamburg, 2014, 2 . 
El nuevo protagonismo de la noción de identidad, sobre todo de las identidades colectivas, que tan decisivamente ha definido la discusión sociopolítica en los últimos decenios, no podía entrar en el programa de investigación de Koselleck. Las identidades -étnicas, nacionales, religiosas- suelen constituirse sobre un pasado común, sobre un acervo de tradiciones $y$, a menudo, de heridas compartidas: son ellas las que traen el pasado con fuerza al presente y recurren para ello a formas varias de memoria y de conocimiento histórico. Pero la historia, dice Koselleck taxativamente, «no tiene la tarea de fundar la identidad, sino de aniquilarla.»" La frase resulta demoledora para las políticas identitarias de hoy, aunque también pondría en cuestión mucha de la ideología que sostuvo a la historiografía como ciencia reina del espíritu en su época gloriosa, cuando los nuevos Estados nacionales la fomentaban para forjar o construir su propia identidad. Sin embargo, lo que está en el punto de mira de Koselleck al formularla no es directamente la política identitaria -en todo caso, presente en el debate alemán de un modo distinto que en el norteamericano ${ }^{43}-$, sino el recurso a la memoria por parte de las nacientes identidades. El carácter subjetivo y emocional de ésta ofrece recuerdos compartidos a partir de los cuales se construiría una identidad colectiva tejida de memoria. Pero Koselleck dedica una buena parte de su argumentación a refutar la posibilidad de que haya recuerdos colectivos, y a evitar que la historia se vea suplantada por la memoria. Es más bien la memoria la que debe dejar paso a la historia. No es fácil determinar cómo establecer en Koselleck esa difícil relación de memoria e historia. Assmann propone condensarla con una paráfrasis freudiana: «Donde había memoria, debe llegar a haber historia». ${ }^{44}$

«Donde había el ello, debe aparecer el yo», era el original de Freud. La paráfrasis forjada por Assmann vincula inequívocamente la memoria con un inconsciente que debe ser sometido con trabajo y paciencia al escrutinio de la instancia racional de la mirada histórica, capaz de ordenar y clasificar los impulsos que salen, inevitablemente, de un fondo irracional e incontrolado. En casi todos los sentidos, le hace justicia a Koselleck. Pues no hay en éste desdén hacia el recuerdo, ni menos aún la pretensión, tan común entre los historiadores conservadores de la Historikerstreit, de proscribir o incluso renunciar al trabajo de la memoria -de las memorias negativas- y hacer que el pasado "pase de una vez». ${ }^{45}$ La memoria -la memoria de las víctimas- da voz al pasado que no quiere pasar; Koselleck estaba de acuerdo en que ese pasado, particularmente el siniestro pasado reciente de Alemania, estaba presente en la sociedad alemana aún más que en la europea, y que no se podía desatender esa presen-

42. R. Koselleck, “Gibt es ein kollektives Gedächtnis?”, discurso del 6-12-2003, en Sofia. Tomado de A. Assmann, Das neue Unbehagen an der Erinnerungskultur. Eine Intervention, Hamburgo, 2014, 20. Énfasis mío.

43. De hecho, tal como muestra agudamente L. Niethammer, Kollektive Identitäten. Hamburgo, 2000, la política de la identidad, que surgió en el debate estadounidense a propósito de las minorías oprimidas, fue hábilmente reaprovechada por el conservadurismo alemán -particularmente los teóricos de la compensación- en favor de una identidad y tradición nacionales.

44. Assmann, Der lange Schatten... op.cit., 205.

45. "El pasado que no quiere pasar" se titulaba el ensayo de Ernst Nolte que desató la controversia. Puede verse toda la documentación del debate en Ernst Reinhard Piper (Dir.): "Historikerstreit". Die Dokumentation der Kontroverse um die Einzigartigkeit der nationalsozialistischen Judenvernichtung, München/Zürich, 1987. 
cia. Reprimir ese pasado, darlo por pasado y despedido, sería negar la propia realidad y, en el caso alemán, rehuir la propia culpa. La atención de Koselleck a la iconología política y a los monumentos funerarios, su retorno repetido sobre los temas relativos al nacionalsocialismo y a la culpa alemana, sus enérgicas intervenciones en los debates públicos sobre las formas pertinentes de recuerdo en la Alemania reunificada, y previamente a eso, sus ensayos sobre los trabajos de Berardt y los sueños en el III Reich, dejan claro que no se trataba para él de reprimir la realidad. En eso se diferenció consciente y explícitamente del bando conservador en Alemania; también de quienes pretendían convertir a los alemanes en víctimas de la guerra. ${ }^{46}$

Lo que no creía tampoco, y aquí se desmarcaba claramente también de Assman o de los herederos de la teoría crítica, es que el recuerdo del pasado y de la consiguiente culpa pudiera convertirse en el motivo fundante de la democracia alemana del futuro, o de cualquier democracia. No porque la culpa y su memoria fueran a debilitar la cohesión de una nación o a cuestionar su identidad -como temían los conservadores- sino porque, a su juicio, no está en la naturaleza del recuerdo el que pueda prolongarse como un recuerdo vivo más allá de la generación que vivió y sufrió los acontecimientos. Este es el punto realmente importante, pues implica, por parte de Koselleck, una teoría particular de la memoria y de la experiencia que resitúa de manera muy coherente, aunque a la par limitada, algunas de las nociones propias de la actualidad a las que nos hemos estado refiriendo. El análisis de esta concepción del recuerdo en Koselleck cerrará este ensayo y nos permitirá entender por qué Koselleck no podía, o no estaba realmente en condiciones, de hacer un diagnóstico de esta época que hemos llamado los últimos cincuenta años.

Para él, el problema de una comunidad política construida sobre el recuerdo constante de las atrocidades pasadas, un recuerdo inscrito en la ley y actualizado institucionalmente, es que, inevitablemente, ese recuerdo se vaciaría. Si Clemençeau les pedía a los franceses, en referencia a la pérdida de Alsacia y Lorena tras la derrota de 1870, "pensar permanentemente en ello, pero no hablarlo nunca ${ }^{47}$, el peligro de la nueva política de la memoria, particularmente en una República Federal, que hiciera del Holocausto y del «nunca más» su fundamento institucional es que, a la inversa de Clemençeau, iba estar siempre hablando de ello sin pensarlo nunca. Las celebraciones rituales quedan muy lejos de la realidad vivida.

Además, por mucho que las instituciones se esfuercen en reactualizar literalmente, simbólicamente, todas las atrocidades pasadas: la distancia en el tiempo y la diversidad de los recuerdos y de los daños es tal que ninguna memoria puede unificarlas. En apenas tres páginas $^{48}$ enumera Koselleck los diferentes tipos de recuerdo que suponen los «seis millones de judíos, cuatro millones y medio de polacos, tres millones y medio de prisioneros rusos (el 60\% del total), los siete millones de civiles de la Unión Soviética, aparte de los soldados caídos, que fueron muchos más, la práctica totalidad de los gitanos, romaníes y nómadas capturados, sin olvidar los 180.000 pacientes definidos como enfermos mentales

46. Véase, en detalle, la edición de Faustino Oncina de Modernidad... op. cit.

47. R. Koselleck, Sinn und Unsinn... op. cit., 242.

48. R. Koselleck, Sinn und Unsinn... op. cit., 257-260 
que estaban en hospitales alemanes.» ${ }^{49}$ Luego, en otra lista de carácter distinto, pero formada también por quienes eran víctimas a la vez que perdedores, y en ocasiones perpetradores, están los millones de alemanes que habitaban los territorios orientales amputados del país tras la derrota, doce millones de ellos forzosamente desplazados al resto de Alemania, otro millón que fue arrastrado prisionero a la Unión Soviética y los dos millones y medio que perdieron la vida al huir o al emigrar. ${ }^{50}$

Basta con repasar todo esto, tratando de atender a todos los matices y diferencias en cada caso, para dar con "estratos del recuerdo cuyo contenido experiencial se les escapa a aquellos a los que no les afectó o que no participaron.» ${ }^{51}$ Por un lado, la pluralidad de los recuerdos no se deja poner sincrónicamente bajo un denominador común -salvo en el duelo, sobre el que volveremos más adelante-. Por otro, y sobre todo, los recuerdos varían diacrónicamente de un tiempo a otro, de los protagonistas a los narradores y a los que los reciben. Para Koselleck, la distinción está entre lo que él llama «experiencias primarias» y «secundarias». ${ }^{52}$ La fuerza y la intensidad de la experiencia primaria, de lo vivido en primera persona por su protagonista, no se deja transmitir ni repetir por nadie, pues las experiencias de esta clase «no son intercambiables ni comunicables [...] siempre pueden compararse, pero sólo desde fuera. Desde la experiencia respectiva de cada uno, todo es único». ${ }^{53}$

¿Qué son estas experiencias directas, en primera persona, de las que el lenguaje, la narración, los símbolos políticos sólo pueden dar un pálido reflejo? Aunque Koselleck está tocando un clásico problema epistemológico sobre el contenido y estructura de la experiencia, lo interesante es cómo lo sitúa en la dialéctica del conocimiento histórico y de la memoria. También lo es -aunque tal vez no podría ser de otro modo-, que recurre a su propia experiencia personal para explicarlo. Cada una de esas millones de víctimas enumeradas arriba tuvo su propia experiencia primaria del Holocausto o de la guerra. Koselleck tuvo la suya, y la contó.

De nuevo, como en tantas otras ocasiones en los alemanes de su generación, la contó tardíamente; es un recuerdo que surge en el año noventa y cinco. Él no pudo ver directamente el Holocausto -e incluso da a menudo a entender que, como soldado, no podía tener conocimiento de él ${ }^{54}$-, pero tiene su propia experiencia primaria que le hace indudable la autenticidad de ese crimen. El relato es ya conocido. Al terminar la guerra, cae prisionero

49. R. Koselleck, Sinn und Unsinn... op. cit., 259

50. R. Koselleck, Sinn und Unsinn... op. cit., 260.

51. R. Koselleck, Sinn und Unsinn... op. cit., 261.

52. Estrictamente, Koselleck distingue entre tres modos fundamentales de experiencia, la primaria y úni$\mathrm{ca}$, la repetida y comunicable, y, finalmente, la que se funda en la reflexión histórica. Véase R. Koselleck, Estratos del tiempo, Barcelona, 2001, 50. Pero en el argumento que seguimos aquí, en los ensayos tardíos de Sentido y sinsentido de la historia, se remite a la diferencia entre la primaria y la secundaria.

53. R. Koselleck, "Glühende Lava zur Erinnerung geronnen. Vielerlei Abschied vom Krieg: Erfahrungen, die austauschbar sind”, en Frankfurter Allgemeine Zeitung, 6/05/1995.

54. Lo cual, como en tantos otros alemanes, puede ser discutible, a tenor de lo que sabemos por el libro Daniel Goldhagen, Los verdugos voluntarios de Hitler. Madrid: Taurus, 1997. 
de los soviéticos, que lo conducen provisionalmente a Auschwitz. Los nuevos carceleros les han contado a los prisioneros los crímenes, los millones de crímenes que los alemanes han perpetrado en ese campo donde están ahora, les han enseñado las cámaras de gas. Los soldados alemanes no dan crédito; para ellos, sólo puede tratarse de propaganda soviética. En la escena que Koselleck describe, los soldados prisioneros están pelando patatas, les vigila un polaco, antiguo interno del campo. Les grita que trabajen más rápido. Está obviamente enfadado, lleno de ira, empoderado sobre los antiguos verdugos. En un momento, agarra un taburete y lo alza por encima de Koselleck. Va a estamparlo contra su cabeza, pero de pronto se detiene, diciendo: «¿Y de qué sirve partirte ahora el cráneo, si ya habéis gaseado a millones?». Lanzó el taburete contra la pared, donde se rompió en pedazos. «De golpe, dice Koselleck, literalmente de golpe, tuve muy claro que decía la verdad. ¿Millones? ¿Gaseados? Eso no podría ser una invención.» ${ }^{55}$

Hay experiencias, continúa Koselleck,

que se derraman y cuajan en el cuerpo como masas de lava ardiente. Son irreversibles, y desde entonces se pueden recuperar en todo momento, inalteradas. No muchas de estas experiencias pueden traducirse a recuerdos auténticos; pero cuando lo hacen, se fundan sobre su presencia sensible. El olor, el sabor, el ruido, el sentimiento y el entorno visible, en suma, todos los sentidos, en el placer o en el dolor, se vuelven a despertar y no precisan de ningún trabajo de la memoria para ser verdaderos y permanecer como verdaderos. ${ }^{56}$

A pesar de no haber presenciado en directo los crímenes de Auschwitz, estos adquirían para él una presencia auténtica, como no podrán tenerla nunca para los millones de turistas que visitan el campo de concentración en medio de un viaje turístico que les conduce, tras la visita, a otros lugares de recreo. Para estos últimos, se trata de una experiencia secundaria, y también lo es para quienes, quizá con menos frivolidad y mayor reflexión sobre el pasado histórico, visitan con respeto ese campo o los monumentos al Holocausto. En cambio, para Koselleck es una experiencia primaria, a pesar de que no fue testigo directo del genocidio.

La escena, aislada y destacada tardíamente en su biografía, no dice mucho más. Pero habla suficientemente de una experiencia de humillación por parte del vencido, de amenaza de muerte y de haberse librado de ella por poco. Una muerte violenta que, dadas las circunstancias, probablemente ni siquiera se habría considerado asesinato, que no se habría castigado como injusta. Más que el testimonio directo, lo que Koselleck describe es el efecto de schock, y el «haberse dado cuenta de golpe de que decía la verdad [sobre los crímenes nazis].»

He destacado en las palabras de Koselleck la expresión de "presencia sensible» con la que él caracteriza su experiencia -gráficamente descrita, además, como masas de lava ardiente- porque está en llamativa consonancia con la reivindicación de la presencia y de

55. R. Koselleck, “Glühende..., op. cit., 4.

56.R. Koselleck, “Glühende...”, op. cit., 4. Énfasis mío. La imagen de la lava ardiente la repetirá Koselleck aún en otros textos. No así la de su experiencia personal. 
las experiencias directas que, hemos visto con Gumbrecht, son propias de los años noventa y siguientes. En todo caso, "presencia» y «sensación» son vocablos requeridos en nuestra modernidad tardía. Koselleck está narrando el vívido recuerdo en primera persona de una experiencia que tuvo cincuenta años antes. Pero lo está narrando en el vocabulario de los años noventa, y el recuerdo que narra se enmarca precisamente dentro de las demandas de la memoria que cobra protagonismo en esos años. Es decir, el recuerdo y el texto de Koselleck se insertan plenamente en el espíritu y el lenguaje de la modernidad postclásica, en la que el Koselleck teórico de la Modernidad era maestro a la vez que crítico.

Para él, esta época no podía ser un ancho presente; tanto menos cuanto que el diagnóstico del ancho presente se planteaba por Gumbrecht como una despedida de la historia conceptual. Pero el «ancho presente» lleva aparejada, a modo de terapia y de "epifanía» ${ }^{57}$, la experiencia como presencia, aunque sea una suerte de experiencia mística -en la literatura, en el arte, en formas de contacto con lo cotidiano-, más genérica que el golpe de realidad que sintió Koselleck al percibir el taburete en manos del ex-prisionero polaco a punto de estamparse sobre su cabeza. Tampoco podía ser una época de reivindicaciones históricas que compensaran funcionalmente la Modernidad, por más que los abogados de la compensación partieran también a las coordenadas de la historia conceptual. La antropología en que se basaba la teoría de la compensación estaba concebida en un espectro mucho más estrecho que las categorías metahistóricas de Koselleck. Finalmente, no podía ser un tiempo de reparación de la Modernidad; aquí su rechazo era claro, pues esa reparación se asocia a la memoria y a la posibilidad de identidades colectivas. Unos correctivos adicionales, los de la memoria, que reajustasen moralmente el mundo moderno no podían partir de un historiador; por más que a él, como muestra la anécdota personal relatada y sugiere la actividad publicística de los últimos años, ese recuerdo le quemase vital e intelectualmente.

Seguramente, entre la reivindicación de una presencia como experiencia primaria que no es ni compensación ni terapia en el ancho presente, y su rechazo de una política de la memoria que funda la legitimidad política sobre los recuerdos negativos, esto es, en el rechazo de estos diagnósticos de los últimos cincuenta años, se encuentra la relación de Koselleck con esta época y también -lo que será mi argumento final- su limitación para diagnosticarla y bautizarla.

Los recuerdos negativos tienen un valor limitado como fundación política del futuro. Es cierto que la legitimidad de la República Federal, tal como estaba además establecido en la Ley Fundamental de 1949, al establecer que la dignidad del ser humano es inviolable, establecía una «obligación que se autoimponen los alemanes a resultas de la experiencia del nacionalsocialismo, de sus crímenes y de sus genocidios en toda Europa y que esto debían recordarlo.» ${ }^{58}$ Con ello se trazaba, por vía del recuerdo, un mínimo normativo que nunca sería lícito traspasar. Y lo que había que retener, entonces, es que

57. Así define Gumbrecht esta experiencia de la presencia, Production... op. cit., 125.

58. R. Koselleck, Von Sinn und Unsinn... op. cit., 246. 
nuestra memoria, medida por las experiencias genuinas de las victimas, aunque estaba preformada de modo negativo, no dejaba de ser secundaria, producto de una elaboración histórica. Nuestras experiencias no son las de los asesinados ni las de los supervivientes. Y esta diferencia negativa será siempre el leit motiv de nuestro recuerdo..$^{59}$

El peligro, finalmente, de pretender transferir el contenido de las experiencias primarias a formas secundarias de recuerdo es que, si además se realiza con ello una suerte de fundación política, se puede estar practicando el juego de otorgar un sentido a lo que no lo tiene: el daño. ¿¿ ese está repitiendo el juego de la teodicea? Sin duda, cabe replicar, la izquierda liberal que plantea programáticamente ese modo negativo de fundación política no pretende de ninguna manera dotar de sentido a una catástrofe siniestra, al modo en que las instituciones religiosas -ya sean las tradicionales o las secularizadas, como el nacionalismo- suelen convertir en mártires o héroes a las víctimas del pasado, arrancándolas de su sufrimiento primario para empotrarlas en una historia de salvación que justifica el presente.

La política del «Nunca más», en cambio, no busca darle un sentido narrativo o heroico al sufrimiento de las víctimas del genocidio nazi; ${ }^{60}$ sino que justamente el «Nunca más» se basa en que esas víctimas lo habían sido de modo absurdo, sin razón ni sentido. No lo fueron para que hubiera después democracia, sino que la democracia es que no vuelva a haberlas: el recuerdo negativo, como die Assmann, «no se dirige al pasado, sino que se entiende como una inversión de futuro.» ${ }^{61}$ Frente a ello, Koselleck insistirá en que «la experiencia de un absurdo sin sentido, marcada a fuego en el cuerpo, en cuanto que es una experiencia primaria, no se deja transmitir a la memoria de otros o al recuerdo de aquellos a los que no les tocó. ${ }^{\text {田 }}$ Todo intento de transmisión, como historia o como memoria, corre el riesgo de convertirse en una logificatio post festum, añade, citando a una de las primeras víctimas judías del nazismo, Theodor Lessing y su Sinngebung des Sinnlosen. ${ }^{62}$

En este punto decisivo, el historiador pensante que era Koselleck fue más historiador que teórico, prefirió anotar la fractura que atraviesa la realidad antes que apostar por una teoría que reunificase o redimiese. Como para Benjamin, como para los herederos de la Escuela de Frankfurt, el tiempo se había convertido para él en el tiempo de un recuerdo negativo, de un pasado siniestro. Pero, a diferencia de ellos, no podía concebir una teoría de la memoria, de la justicia o de la reparación anamnética que rearticulase de modo redentor ese pasado. Escéptico como era, dirigió su atención a la iconología política e investigó en los monumentos funerarios y los modos de recordar u homenajear el pasado. Trabajó como historiador para analizar las variedades y motivaciones del recuerdo. Sin embargo,

59. R. Koselleck, Von Sinn und Unsinn... op. cit., 246.

60. Como sí lo habrían hecho, por cierto, las diversas iglesias o, a menudo, las formas de memoria en los regímenes comunistas de postguerra, que veían a las víctimas como mártires que ofrecían su sacrificio y eran así partícipes de la victoria final.

61. A. Assmann, Ist die Zeit... op.cit., 309.

62. R. Koselleck, Von Sinn und Unsinn... op. cit., 19. Se refiere al libro del pacifista Lessing, Geschichte als Sinngebung des Sinnlosen (La historia como dar sentido a lo que no lo tiene) de 1921. 
en cuanto a la teoría, se quedó en los sugestivos y limitados apuntes de sus últimos textos. Para decidir sobre el recuerdo negativo, sobre la relación entre historia y memoria, debemos respetar de la diferencia irrebasable que existe entre «las experiencias primarias de los que estuvieron realmente afectados y las experiencias secundarias de los actuales, que tienen que elaborarlas a posteriori.» ${ }^{63}$

Ocuparse de eso significa reparar en todas las diferenciaciones y matices que hay en el trabajo de la memoria, de modo que es imposible poner todas las historias de sufrimiento bajo un símbolo de recuerdo común. Este será siempre parcial, como lo es, a su pesar, la Pietá de Käthe Kollwitz en la Neue Wache de Berlín, con la que la Alemania de Kohl trató de saldar cuentas de modo genérico con todo el sufrimiento pasado. ${ }^{64}$ Igualmente falso e injusto es separarlos y discriminarlos en monumentos y recuerdos diferenciados y visitados de manera diferente, como ocurre con la, para él y para otros, más que chocante jerarquía que distingue el vistoso monumento a los judíos asesinados de Europa, en el centro mismo de Berlín, de la mucho más modesta instalación en recuerdo a los gitanos y romaníes asesinados por los nazis, discreta, casi ocultamente dispuesta a sólo trescientos metros del anterior. Se repite así perversamente en el recuerdo la separación de prisioneros por categorías que los propios nazis ejecutaban en el Lager. Frente a ello, él insiste en la necesidad de recordar a todos, a las víctimas en toda su diversidad, -lo que, en el caso alemán cuando menos- llevaría a una multiplicidad casi inabarcable de monumentos. Sólo en el duelo, y por tanto en el dolor, llegan a hacerse todos iguales para el recuerdo.

La indefinición del contenido del dolor, derivada, se diría, de la inexpresabilidad de la experiencia primaria, determina también la imprecisión con que deliberadamente Koselleck dibuja el contenido del recuerdo. A la pregunta de «¿qué recordar?» responde con «hay que intentar tener que pensar lo impensable, aprender a pronunciar lo impronunciable, a representar lo irrepresentable» ${ }^{65}$ : con el recuerdo estamos siempre ante el límite. Es esta inefabilidad del dolor, de la experiencia primaria, lo que hace que el recuerdo se difracte luego en varias modalidades que, en parte, podrán ser elaboradas por la historia. Pero la historia es sólo una modalidad posible de recuerdo, y es ya de una especie diferente.

Además del modo histórico, está la modalidad del recuerdo moral, que juzga y condena, que siempre es necesario, que tiende a convertirse en argumento político. Pero ese recuerdo moral no debe confundirse ni cruzarse con el recuerdo científico, el que procede metodológicamente y acaba por establecer la historia. Uno y otro pueden, acaso, llegar a complementarse, pero se excluyen metodológicamente. Está también, aparte de ellos, el recuerdo religioso, que busca dotar de sentido el sufrimiento pero que solo tiene validez para los creyentes de cada religión y dentro de ella. Finalmente, está la modalidad estética del recuerdo, una especie de sustituto necesario cuando todos los demás fallan, cuando la búsqueda de sentido, de explicación o de juicio fracasa y sólo queda convertir en tema estético

63. R. Koselleck, Von Sinn und Unsinn... op. cit., 246.

64. R. Koselleck, "La discontinuidad del recuerdo", en Memoria... op. cit., 39-51.

65. R. Koselleck, Von Sinn und Unsinn... op. cit., 250. 
la imposibilidad de un recuerdo que otorgue sentido, la imposibilidad de dar una respuesta y simplemente se proponen caminos que hagan pensar al espectador, al lector. Hacer pensar o llamar la atención: nada más puede hacer el recuerdo en su modalidad estética. ${ }^{66}$

Es posible que esta clasificación de modalidades de recuerdo -moral, histórica, religiosa, estética-, por muy precisa que quiera ser, se vea rápidamente amenazada por la fluidez con que unas y otras se pueden cruzar. El recuerdo estético tiene un fuerte componente moral -¿ ¿no es así en la Todesfüge, de Celan?-, y recuerdo moral y político recurre a la estética, ya sea en modo representativo, en los monumentos, ya sea con finalidades pedagógicas: al fin y al cabo, como bien nota Koselleck, la estética mueve a pensar cuando no se sabe qué decir. Tal vez por eso, el interés de Koselleck está más bien en mantener las distinciones, sobre todo entre la memoria y la historia. Un ensayo tardío, del año 2005, aprovecha la controversia alemana sobre si la capitulación del 8 de mayo de 1945 debe considerarse una derrota o una liberación ${ }^{67}$, para trazar las líneas entre la historia y el recuerdo. Las conclusiones son rápidas y taxativas. Los recuerdos son demasiado plurales y contrarios como para poner unificarse; lo son en Europa, entre las naciones y los diferentes grupos étnicos y sociales de los diferentes pueblos. Y lo son también entre los propios alemanes. La pluralidad de los recuerdos puede registrarse en la historia, pero no anularse, ni armonizarse porque no hay un sujeto colectivo de la memoria. «En Europa tenemos una historia común, pero en ningún caso recuerdos comunes.» ${ }^{68}$

La memoria va ligada al juicio moral, y quien juzga moralmente, tiene razón. ¿Cómo no va a tenerla quien recuerda que Alemania es culpable de haber desatado la Guerra Mundial con una brutalidad sin precedentes, y que queda condenada ante la moral y ante el derecho internacional? Pero ese juicio moral sería deshonesto si no cae también sobre otros bandos que cometieron atrocidades en la guerra. En cambio, el análisis histórico buscará las causas y explicaciones de la guerra y del Holocausto por fuera de la moral, combinando factores históricos, sociales, económicos, culturales que permitan construir una narración coherente de lo ocurrido. También aquí resultan aporías y decisiones arbitrarias. ¿Hasta dónde se puede uno remontar en la historia alemana para explicar lo ocurrido? ¿Al Tratado de Versalles? ¿O hasta la Guerra de los Treinta años? Ambos modos de análisis, el moral y el histórico, requieren decisiones y se enredan en sus propias aporías, pero el mayor peligro está en confundirlos, en sostener juicios morales con argumentos históricos, y a la inversa,

Quien se atiene al juicio moral -y eso hay veces que es inexcusable- y quien argumenta de modo causal-genético -y hay veces que este es un camino hipotéticamente sensato- debe tener a la vista las diferencias insalvables que limitan ambos planteamientos. [...] Pues ni los juicios globales de una variante moral o de la causal pueden unificarse con los recuerdos que remiten a las experiencias concretas de los supervivientes. Tanto en el planteamiento científico como en

66. R. Koselleck, Von Sinn und Unsinn... op. cit., 252.

67. R. Koselleck, "Der 8. Mai zwischen Geschichte und Erinnerung”, en Vom Sinn und Unsinn... op .cit., 254-268.

68. R. Koselleck, “El 8 de mayo...”, op. cit., 261. 
la vida cotidiana tenemos que aprender a vivir con diferencias que no se disuelven de hoy para mañana. Tenemos que aprender a soportar las diferencias. ${ }^{69}$

No hay, pues, unificación posible entre la historia y la memoria, entre el juicio moral y las múltiples facetas y perspectivas de lo ocurrido, entre la realidad fáctica de las experiencias primaras y las narraciones en las que se recogen. Por eso, la historia universal no es juicio final -como han pretendido en definitiva todos los progresistas desde Schiller-, ni se resuelve en una comunidad política del recuerdo, sino que las diferencias se deben sostener y resistir. En este alegato en favor de la diferencia frente al impulso unificador y englobante de la memoria se revela el liberal Koselleck; no en vano, el liberalismo ha sido definido cierto que en otro contexto- por Michael Walzer como un arte de la separación. Pero, sobre todo, es lo que le impide encontrar un identificador para el tiempo histórico de los últimos treinta o cuarenta años. Antes bien, parece que Koselleck coloca al historiador fuera de la contienda, en la misión de mediar entre la multiplicidad de los recuerdos y una historia común que mantenga a aquellos separados: una misión que, dice, puede sonar «arrogante o utópica.» ${ }^{70}$ Él sabe que tan utópico es mantener separadas las diferencias como soñar con unificarlas y fundirlas todas.

Pero este recurso a lo utópico, casi como una excusa, y la apelación final al duelo que a todos une, suena curiosamente paradójico en quien trata de mantener la autonomía de la historia. Viene a reconocer que, si es utópica la pretensión de una cultura de la memoria que haga justicia -justicia moral y justicia histórica- a los recuerdos negativos del pasado, esto es el programa de Assmann, también lo es una historia capaz de mantener separados los múltiples recuerdos en conflicto y que sea a la ve una historia común. Pero un historiador no sugiere utopías, menos aún uno como Koselleck. En ningún caso, esta paradoja no le quita valor a su propuesta. Pone tan solo de manifiesto que, en el nuevo cronotopo de los últimos decenios, Koselleck es solo una voz más, la limitada voz del historiador y del testigo del tiempo, pero no del teórico de una nueva temporalidad, como sí lo fue respecto a la temporalidad moderna.

69. R. Koselleck, “El 8 de mayo...”, op. cit., 264.

70. R. Koselleck, “El 8 de mayo..., op. cit., 264. 